\title{
Growth inhibitory properties of Backhousia myrtifolia Hook. \& Harv. and Syzygium anisatum (Vickery) Craven \& Biffen extracts against a panel of pathogenic bacteria
}

\author{
Krystal Bryant ${ }^{1}$ and lan Edwin Cock ${ }^{1,2^{*}}$ \\ 'School of Natural Sciences, Griffith University, 170 Kessels Rd, Nathan, Brisbane, Queensland 4111, AUSTRALIA. \\ 2Environmental Futures Research Institute, Griffith University, 170 Kessels Rd, Nathan, Brisbane, Queensland 4111, AUSTRALIA.
}

\begin{abstract}
Introduction: $B$. myrtifolia and $S$. anisatum are native Australian trees with uses as traditional medicines and bushfoods. Essential oils produced from leaves of these species have reputed antiseptic properties. Despite this, B. myrtifolia and $S$. anisatum leaf solvent extractions have not been rigorously examined for antibacterial properties against many pathogens. Methods: The antimicrobial activity of aqueous and methanolic leaf extracts of B. myrtifolia and $S$. anisatum was investigated by disc diffusion and growth time course assays against a panel of pathogenic bacteria. The growth inhibitory activity was quantified by MIC determination. Toxicity was determined using the Artemia franciscana nauplii bioassay. Results: Methanolic and aqueous B. myrtifolia and S. anisatum leaf extracts inhibited the growth of a wide range of bacterial species. Growth of both gram positive and gram negative bacteria was inhibited the $B$. myrtifolia and $S$. anisatum extracts to approximately the same extent. In general, $S$. anisatum extracts were more potent inhibitors of bacterial growth than were the B. myrtifolia extracts, and (with some noteable exceptions) the methanolic extracts were generally more potent than the aqueous extracts. The B. myrtifolia and $S$. anisatum extracts were particularly potent inhibitors of $P$. mirabilis growth, with MIC values as low as $105 \mu \mathrm{g} / \mathrm{mL}$ (aqueous $S$. anisatum extract). The antibacterial activity of the methanolic B. myrtifolia and
\end{abstract}

S. anisatum extracts were further investigated by growth time course assays which showed significant growth inhibition in cultures of $E$. coli, $K$. pneumpniae and $P$. mirabilis within $1 \mathrm{~h}$ of exposure. All extracts were determined to be nontoxic in the Artemia franciscana nauplii bioassay, indicating their safety for internal use as well as for topical uses. Conclusions: The lack of toxicity of the B. myrtifolia and $S$. anisatum extracts and their growth inhibitory bioactivity against a panel of pathogenic bacteria partially validate Australian Aboriginal usage of these species as antiseptic agent and indicate their potential in the development of antiseptic agents.

Key words: Backhousia myrtifolia, Syzygium anisatum, Cinnamon myrtle, Anise myrtle, Australian plants, Antibacterial activity, Medicinal plants.

\section{Correspondence:}

Ian Edwin Cock, School of Natural Sciences, Griffith University, 170 Kessels Rd, Nathan, Brisbane, Queensland 4111, AUSTRALIA. Phone no: +61 7 37357637; Fax: +61 737355282

E-mail: I.Cock@griffith.edu.au (I. E. Cock)

DOI : $10.5530 /$ pc.2016.4.2

\section{INTRODUCTION}

The therapeutic potential of the aromatic flora of Australia has been recognised for many thousands of years. The first Australians had welldeveloped ethnopharmacological systems and understood the therapeutic properties of a wide variety of aromatic Australian plants. ${ }^{1}$ More recently, Sir Joseph Banks (the botanist aboard Captain James Cook's voyage of the Endeavour) coined the phrase tea tree' for the endemic Australian plant Melaleuca alternifolia due to similarities in use with Camellia sinensis, and some of its perceived therapeutic properties. ${ }^{1}$ Nowadays, a thriving trade exists, with 'Tea Tree' essential oils marketed globally. Similarly, the therapeutic properties of Eucalyptus spp. are well documented. ${ }^{2,3}$ Plants of the genus Eucalyptus are now recognised for their potent antimicrobial activities and are commonly used as topical antiseptics. More recently, the bacterial growth inhibitory properties of many genera within the family Myrtaceae have been documented. In particular, Callistemon spp., ${ }^{4}$ Eugenia spp., ${ }^{1}$ Kunzea spp.,,${ }^{1,5}$ Leptospermum ${ }^{1}$ and Syzygium spp. ${ }^{6-8}$ have been reported to inhibit the growth of a wide panel of bacteria, including many medicinally important pathogens. Despite this, the antibacterial properties of several Myrtaceae are yet to be rigorously examined. Backhousia myrtifolia Hook. \& Harv. (Figure 1a) is a medium tree which is native to subtropical rainforest areas of eastern Australia. The leaves of this plant are dried to produce 'cinnamon myrtle', which is used as an herb and food flavouring. ${ }^{9}$ Studies in our laboratory ${ }^{10}$ and elsewhere ${ }^{11,12}$ have demonstrated the antibacterial activity of leaves of the taxonomically related species Backhousia citriodora F. Muell. (commonly known as lemon myrtle). Interestingly, no reports of Aboriginal medicinal use of either B. citriodora or B. myrtifolia were found in the literature, although the leaves of both species were used in cooking. Most of the studies of Backhousia spp. antibacterial potential focus on the essential oil of the leaves. ${ }^{11,12}$ In most plants of this genus, the levels and composition of the essential oil terpenoid components receives the most interest. In particular, the monoterpenoid composition of Backhousia spp. has been extensively reported. B. citriodora essential oils contain more than $90 \%$ citral, which comprises a mixture of neral ( $\alpha$-citral; Figure $1 c)$ and geranial $(\beta$-citral; Figure $1 \mathrm{~d}) .^{13}$ Both neral and geranial have been previously reported to have potent antibacterial activity against a variety of bacteria. ${ }^{11,14,15}$ Similarly, the high monoterpenoid composition of B. myrtifolia essential oils is known, with methyl eugenol (Figure 1e) and elemicin (Figure 1f) recognised as the major components. The antiseptic properties of these compounds is also well established. ${ }^{16}$

Syzygium anisatum (Vickery) Craven \& Biffen (Figure 1b; formerly Backhousia anisata; commonly known as anise myrtle) is a related species which has a similar but limited occurrence in eastern Australian subtropical rainforests. ${ }^{1}$ As for Backhousia spp., S. anisatum is used as a bushfood spice and the leaves are distilled for the essential oil, which is rich in anethole (anise camphor; Figure 1g) and chavicol (Figure 1h). Anethole and chavicol have potent bactericidal activity, with minimum bactericidal activities (MBC) as low as $100 \mu \mathrm{g} / \mathrm{mL} .{ }^{17}$ Despite this, studies into the antibacterial properties of $S$. anisatum extracts towards many bacterial pathogens are lacking. 

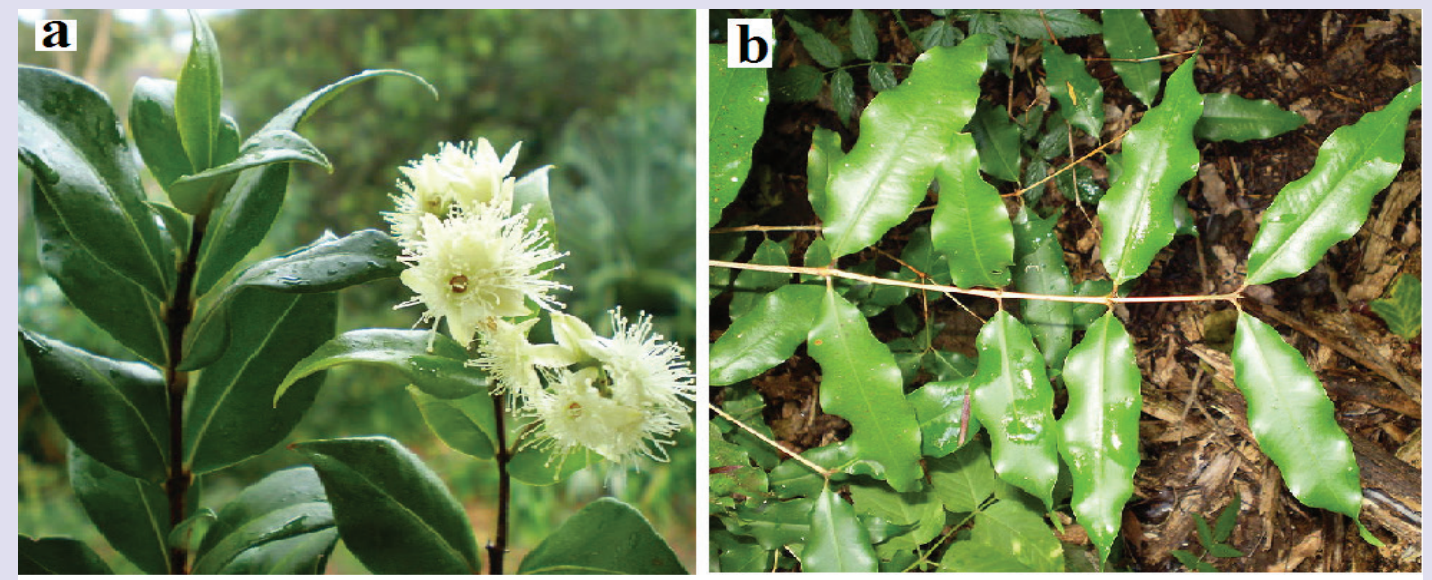<smiles>CC(C)=CCCC(C)C=O</smiles>

$\mathbf{C}$<smiles>CC(C)=CCCC(C)=CC=O</smiles>

d

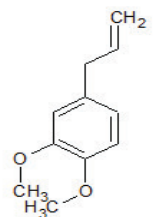

$\mathbf{e}$<smiles>C=CCc1ccc(OC)c(OC)c1OC</smiles>

f<smiles>C/C=C/c1ccc(OC)cc1</smiles>

$\mathbf{g}$

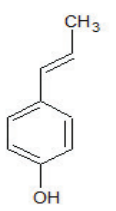

h

Figure 1: (a) B. myrtifolia and (b) S. anisatum leaves as well as the chemical structures of the terpenoid components (c) neral (a-citral), (d) geranial ( $\beta$-citral), (e) methyl eugenol, (e) elemicin, ( $\mathrm{g}$ ) anethole and (h) chavicol.

Most of the studies reporting antibacterial properties for Backhousia spp. and Syzygium spp. have examined essential oils. The use of essential oils for the testing of antimicrobial activity can be problematic. The relative insolubility of many of the oil components retards their diffusion through agar gels in agar dilution or disc diffusion studies. Many studies have utilised solubilising agents (eg. Tween 80 ) to aid oil component diffusion, resulting in variable results. ${ }^{18,19}$ Solubilising agents appear to increase the susceptibility of some bacteria to antimicrobial agents, decrease the susceptibility of others, whilst having no effect on yet other bacteria. Recent studies have reported the antibacterial activity of methanolic extracts of B. citriodora leaves against a panel of bacteria. ${ }^{10}$ The current report was undertaken to extend those studies to examine 2 taxonomically related Myrtaceae spp. (B. myrtifolia and S. anisatum) for similar growth inhibitory properties against a panel of pathogenic bacteria.

\section{MATERIALS AND METHODS}

\section{Plant collection and extraction}

Backhousia myrtifolia Hook. \& Harv. and Syzygium anisatum (Vickery) Craven \& Biffen leaves were obtained from and identified by Philip Cameron, senior botanic officer, Mt Cootha Botanical Gardens, Brisbane, Australia. Leaf samples were dried in a Sunbeam food dehydrator and stored at $-30^{\circ} \mathrm{C}$. Prior to use, the leaves were freshly ground to a coarse powder and $1 \mathrm{~g}$ quantities were weighed into separate tubes. A volume of $50 \mathrm{~mL}$ methanol (Ajax, Australia; AR grade) or sterile deionised water were added to individual tubes and extracted for $24 \mathrm{hrs}$ at $4^{\circ} \mathrm{C}$ with gentle shaking. The extracts was filtered through filter paper (Whatman No. 54) under vacuum, followed by drying by rotary evaporation in an Eppendorf concentrator 5301. The resultant pellets were dissolved in $10 \mathrm{~mL}$ sterile deionised water (containing 1\% DMSO). The extracts were passed through $0.22 \mu \mathrm{m}$ filter (Sarstedt) and stored at $4^{\circ} \mathrm{C}$ until use.

\section{Qualitative phytochemical studies}

Phytochemical analysis of the B. myrtifolia and S. anisatum leaf extracts for the presence of saponins, phenolic compounds, flavonoids, phytosteroids, triterpenoids, cardiac glycosides, anthraquinones, tannins and alkaloids was conducted by previously described assays. ${ }^{20-21}$

\section{Antibacterial screening} Test microorganisms

All media was supplied by Oxoid Ltd., Australia. Reference strains of Klebsiella pneumoniae (ATCC31488), Escherichia coli (ATCC 25922) and Proteus mirabilis (ATCC21721) were purchased from American Tissue Culture Collection, USA. Clinical isolate microbial strains of Aeromonas hydrophilia, Alcaligenes feacalis, Bacillus cereus, Citrobacter freundii, E. coli, K. pneumoniae, P. mirabilis, Pseudomonas fluorescens, Salmonella newport, Serratia marcescens, Shigella sonneii, Staphylococcus aureus, Staphylococcus epidermidis and Streptococcus pyonenes were obtained from Ms Michelle Mendell and Ms Jane Gifkins, Griffith University. All stock cultures were subcultured and maintained in nutrient broth at $4^{\circ} \mathrm{C}$.

\section{Evaluation of antimicrobial activity}

Antimicrobial activity of all plant extracts was determined using a modified disc diffusion assay. ${ }^{22-24}$ Briefly, $100 \mu \mathrm{L}$ of each bacterial culture was grown in $10 \mathrm{~mL}$ of fresh nutrient broth until they reached a count of $\sim 10^{8}$ cells $/ \mathrm{mL}$. A volume of $100 \mu \mathrm{L}$ of the bacterial suspension was spread onto nutrient agar plates and extracts were tested for antibacterial activity using $5 \mathrm{~mm}$ sterilised filter paper discs. Discs were infused with $10 \mu \mathrm{L}$ of the plant extracts, allowed to dry and placed onto the inoculated plates. The plates were allowed to stand at $4^{\circ} \mathrm{C}$ for $2 \mathrm{~h}$ before incubation at $30^{\circ} \mathrm{C}$ for $24 \mathrm{~h}$. The diameters of the inhibition zones were measured to the closest whole millimetre. Each assay was performed in at least triplicate. Mean values $( \pm$ SEM) are reported in this study. Standard discs of ampicillin $(10 \mu \mathrm{g})$ were obtained from Oxoid, Australia and were used 
Table 1: The mass of dried extracted material, the concentration after resuspension in deionised water and qualitative phytochemical screenings of the aqueous and methanolic B. myrtifolia and S. anisatum extracts

\begin{tabular}{|c|c|c|c|c|c|c|c|c|c|c|c|c|c|c|c|c|}
\hline $\begin{array}{l}\frac{\tilde{u}}{u} \\
\tilde{y} \\
\tilde{n} \\
\stackrel{\tilde{c}}{\alpha} \\
\frac{\pi}{\alpha}\end{array}$ & 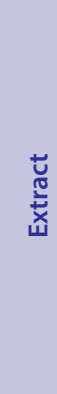 & 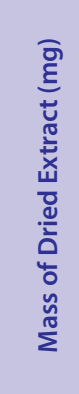 & 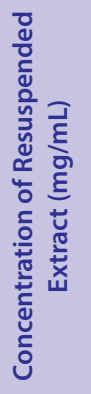 & 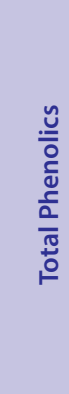 & 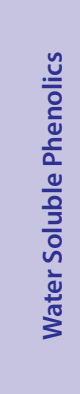 & 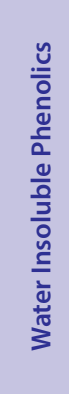 & 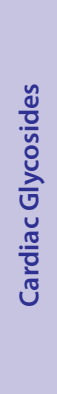 & 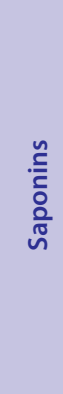 & 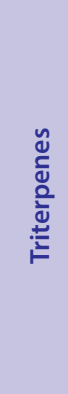 & 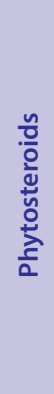 & 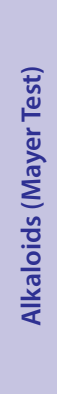 & 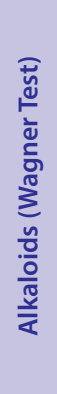 & 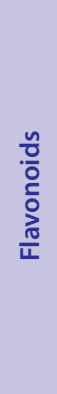 & & 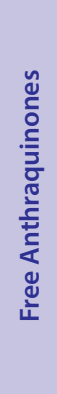 & 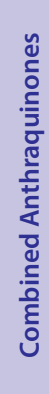 \\
\hline 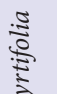 & $\mathrm{M}$ & 253 & 25.3 & +++ & +++ & + & - & ++ & ++ & - & - & - & + & ++ & - & - \\
\hline$\stackrel{\Xi}{\equiv}$ & $\mathrm{W}$ & 178 & 17.8 & +++ & +++ & ++ & - & + & + & - & - & - & + & + & - & - \\
\hline 蔦 & $\mathrm{M}$ & 165 & 16.5 & +++ & +++ & ++ & - & + & ++ & - & - & - & + & ++ & - & - \\
\hline $\begin{array}{l}\text { है } \\
\text { जे }\end{array}$ & $\mathrm{W}$ & 118 & 11.8 & +++ & +++ & ++ & - & + & ++ & - & - & - & + & ++ & - & - \\
\hline
\end{tabular}

+++ indicates a large response; ++ indicates a moderate response; + indicates a minor response; - indicates no response in the assay. $\mathrm{M}=$ methanolic extract; $\mathrm{W}=$ aqueous extract.

as positive controls to compare antibacterial activity. Filter discs infused with $10 \mu \mathrm{L}$ of distilled water were used as a negative control.

\section{Minimum inhibitory concentration (MIC) determination}

The minimum inhibitory concentration (MIC) of each extract against susceptible bacteria was determined as previously described. ${ }^{25,26}$ Briefly, the plant extracts were diluted in deionised water and tested across a range of concentrations. Discs were infused with $10 \mu \mathrm{L}$ of the test dilutions, allowed to dry and placed onto inoculated plates. The assay was completed as outlined above and graphs of the zone of inhibition versus concentration were plotted for each extract. Linear regression was used to determine the MIC values of each extract.

\section{Bacterial growth time course assay}

Bacterial growth time course studies were performed as previously described. ${ }^{27}$ Briefly, $3 \mathrm{~mL}$ of the ATCC reference bacterial cultures (Klebsiella pneumoniae (ATCC31488), Escherichia coli (ATCC 25922) and Proteus mirabilis (ATCC21721)) in nutrient broth were added to $27 \mathrm{~mL}$ nutrient broth containing $3 \mathrm{~mL}$ of $10 \mathrm{mg} / \mathrm{mL}$ methanolic plant extract to give a final concentration of $1000 \mu \mathrm{g} / \mathrm{mL}$ in the assay. The tubes were incubated at $30^{\circ} \mathrm{C}$ with gentle shaking. The optical density was measured hourly at $550 \mathrm{~nm}$ for a $6 \mathrm{~h}$ incubation period. Control tubes were incubated under the same conditions but without the extract. All assays were performed in triplicate.

\section{Toxicity screening}

\section{Reference toxin for toxicity screening}

Potassium dichromate $\left(\mathrm{K}_{2} \mathrm{Cr}_{2} \mathrm{O}_{7}\right)$ (AR grade, Chem-Supply, Australia) was prepared as a $4 \mathrm{mg} / \mathrm{mL}$ solution in distilled water and was serially diluted in artificial seawater for use in the Artemia franciscana nauplii bioassay.

\section{Artemia franciscana nauplii toxicity screening}

Toxicity was tested using an adapted Artemia franciscana nauplii lethality assay. ${ }^{28-30}$ Briefly, $400 \mu \mathrm{L}$ of seawater containing approximately 46 (mean $46.2, n=125$, SD 12.5) A. franciscana nauplii were added to wells of a 48 well plate and immediately used for bioassay. A volume of $400 \mu \mathrm{L}$ of diluted plant extracts or the reference toxin were transferred to the wells and incubated at $25 \pm 1{ }^{\circ} \mathrm{C}$ under artificial light (1000 Lux). A $400 \mu \mathrm{L}$ seawater negative control was run in triplicate for each plate. All treatments were performed in at least triplicate. The wells were checked at regular intervals and the number of dead counted. The nauplii were considered dead if no movement of the appendages was detected within 10 seconds. After $24 \mathrm{~h}$, all nauplii were sacrificed and counted to determine the total $\%$ mortality per well. The $\mathrm{LC}_{50}$ with $95 \%$ confidence limits for each treatment was determined using probit analysis.

\section{Statistical analysis}

Data are expressed as the mean \pm SEM of at least three independent experiments. One way ANOVA was used to calculate statistical significance between control and treated groups with a $P$ value $<0.01$ considered to be statistically significant.

\section{RESULTS}

\section{Liquid extraction yields and qualitative phytochemical screening}

Extraction of $1 \mathrm{~g}$ of B. myrtifolia and S. anisatum leaves with methanol or deionised water yielded dried extracts ranging from $118 \mathrm{mg}$ (aqueous S. anisatum extract) to $253 \mathrm{mg}$ (methanolic B. myrtifolia extract) (Table 1). Higher extraction yields were determined for both the B. myrtifolia extracts than for the corresponding $S$. anisatum extracts. The dried extracts were resuspended in $10 \mathrm{~mL}$ of deionised water (containing $1 \%$ DMSO), resulting in the extract concentrations shown in Table 1.

Qualitative phytochemical studies showed that all solvents extracted similar classes of phytochemicals. All had high levels of phenolics (high levels of water soluble phenolics, moderate levels of water insoluble phenolics). Generally, all extracts also contained moderate levels of triterpenoids and tannins, as well as low levels of flavonoids. All extracts were generally devoid of all other classes of phytochemicals.

\section{Antimicrobial activity}

To determine the growth inhibitory activity of the B. myrtifolia and S. anisatum extracts against the panel of pathogenic bacteria, aliquots 


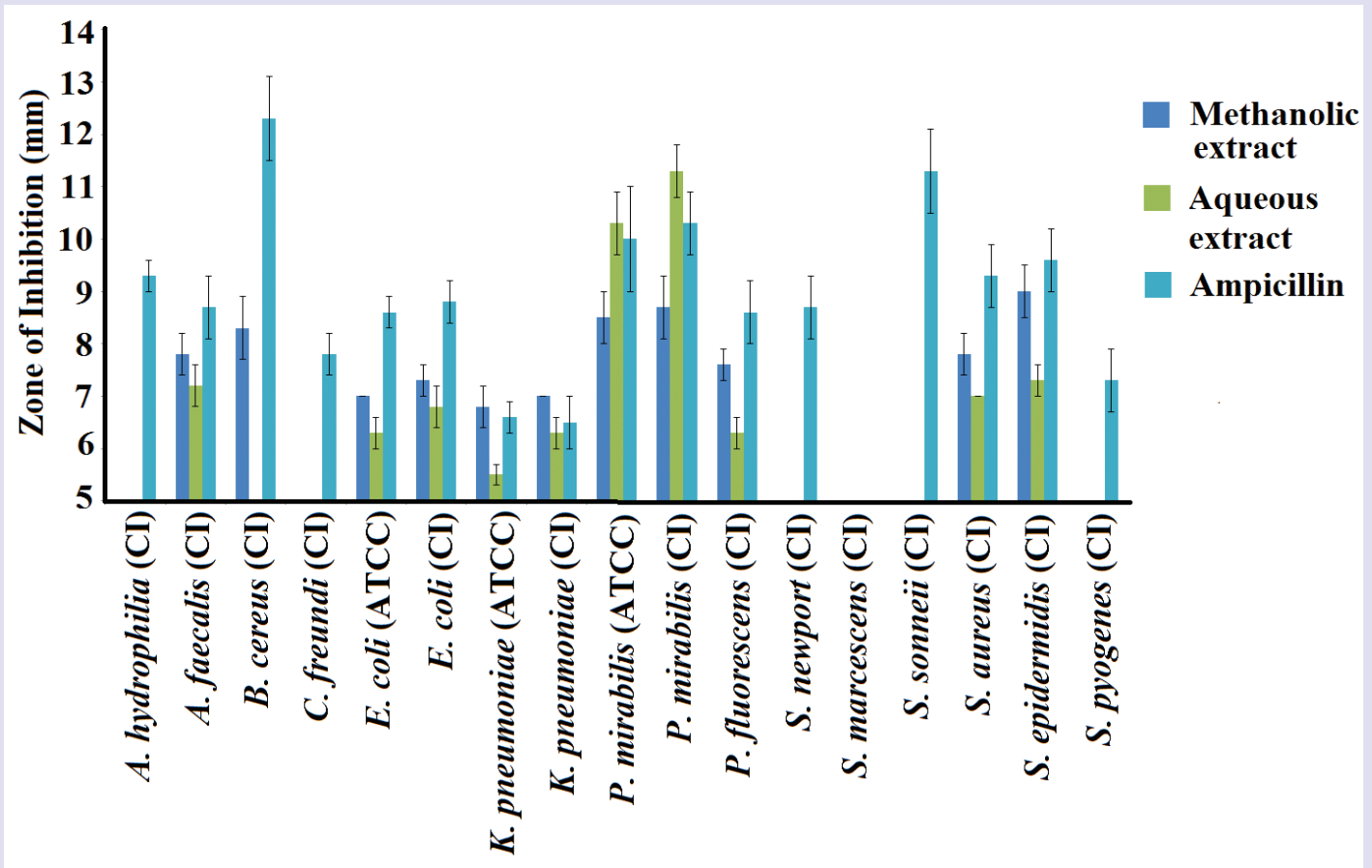

Figure 2: Growth inhibitory activity of aqueous and methanolic B. myrtifolia leaf extracts against the clinical isolate $(\mathrm{Cl})$ and reference (ATCC) bacterial strains measured as zones of inhibition $(\mathrm{mm}) \pm$ SEM. Blue bars represent inhibition by methanolic B. myrtifolia extracts; green bars represent inhibition by aqueous B. myrtifolia extracts; aqua bars represent the inhibition by the ampicillin control. Amp = ampicillin $(10 \mu \mathrm{g})$ control. All determinations were in at least triplicate and the results are expressed as mean zones of inhibition $(\mathrm{mm}) \pm \mathrm{SEM}$.

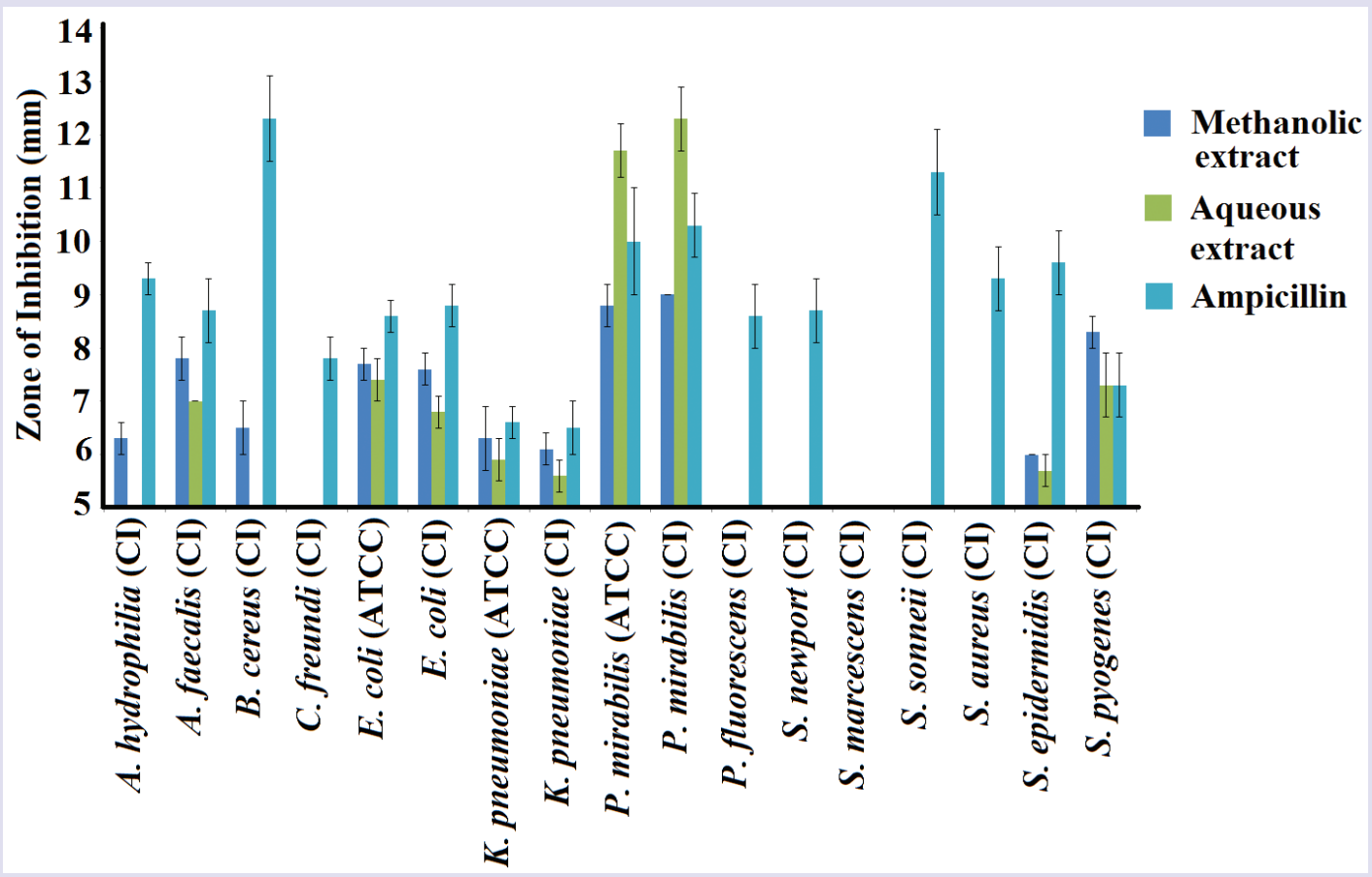

Figure 3: Growth inhibitory activity of aqueous and methanolic S. anisatum leaf extracts against the clinical isolate $(\mathrm{Cl})$ and reference (ATCC) bacterial strains measured as zones of inhibition $(\mathrm{mm}) \pm$ SEM. Blue bars represent inhibition by methanolic S. anisatum extracts; green bars represent inhibition by aqueous $S$. anisatum extracts; aqua bars represent the inhibition by the ampicillin control. Amp = ampicillin $(10 \mu \mathrm{g})$ control. All determinations were in at least triplicate and the results are expressed as mean zones of inhibition $(\mathrm{mm}) \pm$ SEM. 


\begin{tabular}{|c|c|c|c|c|c|}
\hline \multirow{2}{*}{$\begin{array}{l}\text { Bacterial } \\
\text { Species }\end{array}$} & \multirow{2}{*}{ Strain } & \multicolumn{2}{|c|}{ B. myrtifolia } & \multicolumn{2}{|c|}{ S. anisatum } \\
\hline & & M & w & M & w \\
\hline A. hydrophilia & Clinical isolate & - & - & $>10,000$ & - \\
\hline A. feacalis & Clinical isolate & 5081 & 5405 & 1792 & 3284 \\
\hline B. cereus & Clinical isolate & 3700 & - & $>10,000$ & - \\
\hline C. freundii & Clinical isolate & - & - & - & - \\
\hline E. coli & ATCC: 25922 & $>10,000$ & $>10,000$ & 893 & 3363 \\
\hline E. coli & Clinical isolate & $>10,000$ & $>10,000$ & 1255 & 3884 \\
\hline K. pneumoniae & ATCC: 31488 & $>10,000$ & $>10,000$ & 4339 & $>10,000$ \\
\hline K. pneumoniae & Clinical isolate & $>10,000$ & $>10,000$ & 5150 & $>10,000$ \\
\hline P. mirabilis & ATCC:21721 & 1183 & 307 & 885 & 289 \\
\hline P. mirabilis & Clinical isolate & 837 & 125 & 623 & 105 \\
\hline P. fluorescens & Clinical isolate & 4538 & $>10,000$ & - & - \\
\hline S. newport & Clinical isolate & - & - & - & - \\
\hline S. marcescens & Clinical isolate & - & - & - & - \\
\hline S. sonneii & Clinical isolate & - & - & - & - \\
\hline S. aureus & Clinical isolate & 2760 & 3873 & - & - \\
\hline S. epidermidis & Clinical isolate & 2322 & 1755 & $>10,000$ & $>10,000$ \\
\hline S. pyonenes & Clinical isolate & - & - & 1684 & 4190 \\
\hline
\end{tabular}

Numbers indicate the mean MIC and $\mathrm{LC}_{50}$ values of triplicate determinations. - indicates no inhibition. $\mathrm{M}=$ methanolic extract; $\mathrm{W}=$ aqueous extract.

$(10 \mu \mathrm{L})$ of each extract were screened in the disc diffusion assay. Aqueous and methanolic B. myrtifolia extracts inhibited a broad spectrum of the bacterial species screened (Figure 2). The methanolic B. myrtifolia extract was a more potent growth inhibitor than the aqueous extract against most bacterial species (as assessed by the sizes of the zones of inhibition). Noteably, the opposite trend was noted for P. mirabilis growth inhibition, with the aqueous extracts inhibiting the reference and clinical strains by $10.3 \pm 0.6$ and $11.3 \pm 0.6 \mathrm{~mm}$ respectively. This inhibition was particularly noteworthy compared to the inhibition by the ampicillin control $(10 \mu \mathrm{g}$ : inhibition zones of approximately $10 \mathrm{~mm})$ In contrast, the methanolic B. myrtifolia extract inhibited P. mirabilis growth by $8.5 \pm 0.6 \mathrm{~mm}$ (reference strain) and $8.6 \pm 0.6 \mathrm{~mm}$ (clinical isolate strain). Similar bacterial growth inhibitory trends were noted for the S. anisatum extracts (Figure 3). As reported for the B. myrtifolia extracts, P. mirabilis was more susceptible to growth inhibition by the $S$. anisatum extracts than were the other bacterial species screened. Indeed, inhibition zones of $11.7 \pm 0.5 \mathrm{~mm}$ and $12.3 \pm 0.6 \mathrm{~mm}$ were measured for the inhibition of the aqueous extract against the reference and clinical isolate strains of P. mirabilis respectively.

Both gram positive and gram negative bacteria were affected by the B. myrtifolia and S. anisatum extracts. Of the 10 gram negative bacterial strains tested, $5(50 \%)$ and $4(40 \%)$ were inhibited by methanolic and aqueous $B$. myrtifolia leaf extracts respectively. S. anisatum extracts had a similar profile, inhibiting the same numbers of gram negative bacteria as the corresponding B. myrtifolia extracts. In contrast, the methanolic $B$. myrtifolia and S. anisatum extracts inhibited 3 of the 4 (75\%) of the gram positive bacterial species tested respectively whilst both of the aqueous extracts inhibited the growth of only 1 of the 4 gram positive species tested (25\%).

The antimicrobial efficacy was further quantified by determining the MIC values for each extract against the microbial species which were determined to be susceptible. The methanolic and aqueous extracts of both species were potent growth inhibitors of several bacterial species (as judged by MIC; Table 2). P. mirabilis was the most susceptible bacteria to the B. myrtifolia and S. anisatum extracts, with MIC values generally $<1000 \mu \mathrm{g} / \mathrm{mL}(<10 \mu \mathrm{g}$ infused into the disc). The aqueous extracts of both species were particularly potent $P$. mirabilis growth inhibitors. MIC values of 307 and $125 \mu \mathrm{g} / \mathrm{mL}$ were determined for aqueous $B$. myrtifolia extract against the reference and clinical strains of the bacterium respectively. The aqueous $S$. anisatum extract was a similarly potent growth inhibitor, with MIC values of 289 (reference P. mirabilis strain) and $105 \mu \mathrm{g} / \mathrm{mL}$ (clinical isolate $P$. mirabilis strain). The methanolic extracts were also potent $P$. mirabilis growth inhibitors, albeit with slightly higher MIC values (in the $600-1200 \mu \mathrm{g} / \mathrm{mL}$ range). As $P$. mirabilis infection is a common cause of urinary tract infections and has also been identified as a trigger of rheumatoid arthritis, ${ }^{31,32} \mathrm{~B}$. myrtifolia and S. anisatum extracts have potential for the prevention of these diseases in genetically susceptible individuals.

The methanolic S. anisatum extract was also a potent $E$. coli growth inhibitor (MIC's of approximately $900-1200 \mu \mathrm{g} / \mathrm{mL}$ against the different bacterial strains). The aqueous and methanolic $S$. anisatum extracts were also moderate inhibitors of $A$. feacalis and S. pyonenes, and inhibited $K$. pneumoniae with lower potency. In contrast, aqueous and methanolic $B$. myrtifolia extracts were moderate inhibitors of $S$. aureus and $S$. epidermidis growth. The methanolic B. myrtifolia extract (but not the aqueous $B$. myrtifolia extract) was also a moderate inhibitor of $B$. cereus and $P$. fluorescens growth. Low growth inhibition (or no inhibition) was noted for all other extract/bacterium combinations, with MIC values $>5000 \mu \mathrm{g} / \mathrm{mL}$.

\section{Bacterial growth time course assay}

The antibacterial activity of the B. myrtifolia and S. anisatum extracts was further investigated in the reference bacterial strains by bacterial growth time course assays in the presence and absence of the extract. 

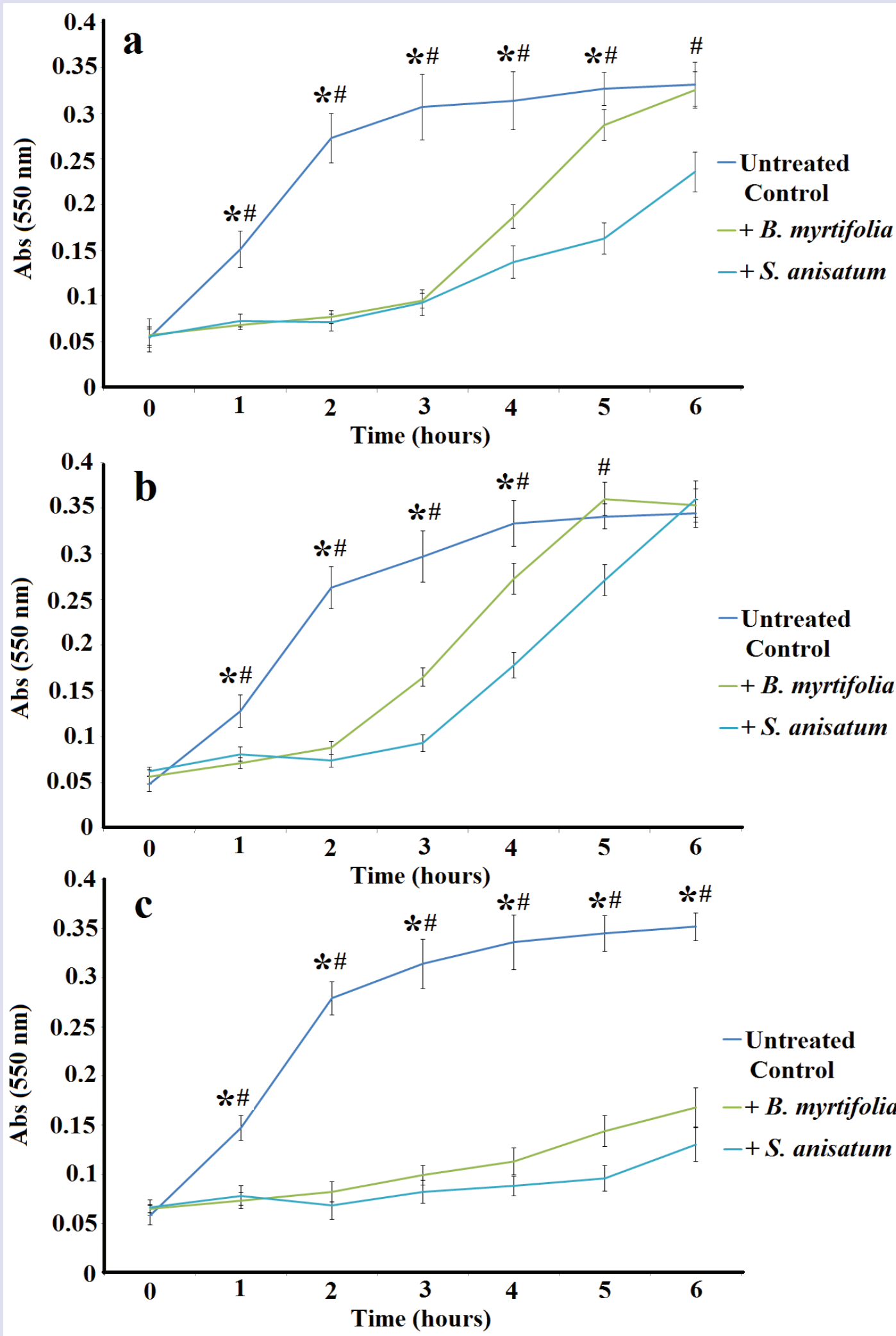

Figure 4: Bacterial growth curves for (a) E. coli, (b) K. pneumoniae, (c) P. mirabilis. All bioassays were performed in at least triplicate and are expressed as mean $\pm \mathrm{SEM}$. ${ }^{*}=$ growth results in the presence of methanolic $B$. myrtifolia extract that are significantly different to the untreated control growth $(p<0.01)$; \# = growth results in the presence of methanolic $S$. anisatum extract that are significantly different to the untreated control growth $(p<0.01)$. 


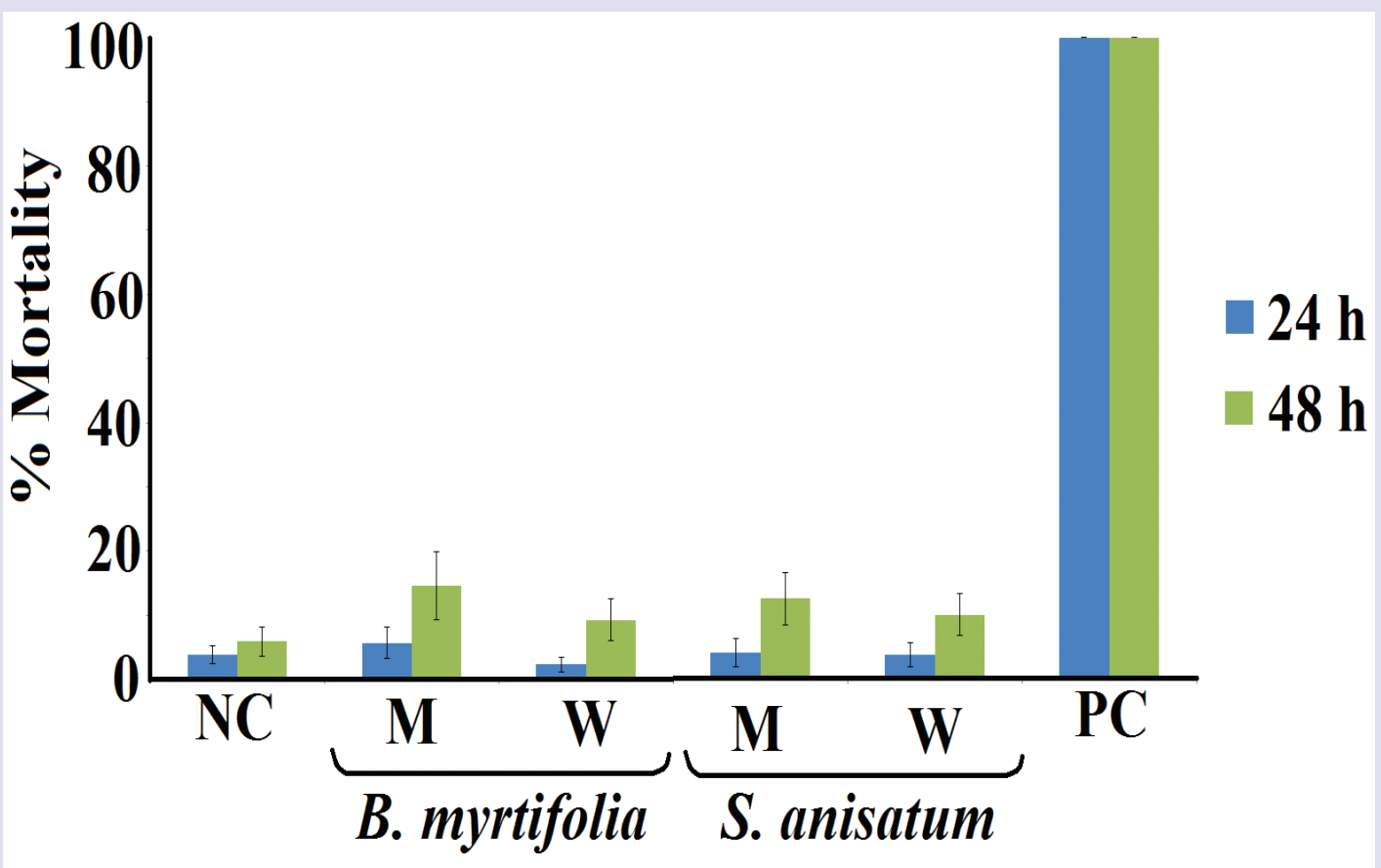

Figure 5: The lethality of the aqueous and methanolic B. myrtifolia and S. anisatum leaf extracts $(2000 \mu \mathrm{g} / \mathrm{mL})$, potassium dichromate $(1000 \mu \mathrm{g} / \mathrm{mL})$ and a seawater control. $M=$ methanolic extract; $W=$ aqueous extract; $N C=$ negative (seawater) control; $\mathrm{PC}=$ positive control $(1000 \mu \mathrm{g} / \mathrm{mL}$ potassium dichromate). All bioassays were performed in at least triplicate and are expressed as mean \pm SEM.

As the methanolic extracts were generally more potent than the aqueous extracts (except for $P$. mirabilis inhibition where aqueous extracts were more potent), only the effect of the methanolic extracts on bacterial growth time course was examined. The starting concentration of the extract used in these assays was $1000 \mu \mathrm{g} / \mathrm{mL}$. Methanolic extracts of both B. myrtifolia and S. anisatum significantly inhibited E. coli (Figure 4a), K. pneumoniae (Figure 4b) and P. mirabilis (Figure 4c) growth within $1 \mathrm{~h}$, indicating a rapid antimicrobial action. Whilst $E$. coli and K. pneumoniae growth was inhibited for at least the first 4 hours of the time course, these bacteria were generally able to overcome this inhibition by $6 \mathrm{~h}$, with the recorded turbidity not significantly different to that of the untreated control. This indicates that the growth inhibition of these bacteria was bacteriostatic for the methanolic B. myrtifolia and S. anisatum extracts at the concentrations tested. In contrast, inhibition of $P$. mirabilis by the methanolic $B$. myrtifolia and $S$. anisatum extracts was substantially more profound, with growth still significantly inhibited by the end of the $6 \mathrm{~h}$ time course study. This may indicate that these extracts have bactericidal activity against $P$. mirabilis at the dose tested.

\section{Quantification of toxicity}

The toxicity of the B. myrtifolia and S. anisatum extracts was initially tested in the Artemia franciscana nauplii bioassay at a concentration of $2000 \mu \mathrm{g} / \mathrm{mL}$ (Figure 5). All extracts induced low levels of mortality at 24 and $48 \mathrm{~h}$, similar to the \% mortality seen for the seawater control. As none of the extracts induced toxicity significantly different from the seawater control, all were deemed to be nontoxic. In contrast, the potassium dichromate positive controls induced mortality within $4 \mathrm{~h}$ (results not shown), with $100 \%$ mortality induction seen by $24 \mathrm{~h}$.

To further quantify the effect of toxin concentration on the induction of mortality, the extracts were serially diluted in artificial seawater to test

\begin{tabular}{|c|c|c|}
\hline \multirow{2}{*}{ Extract } & \multicolumn{2}{|c|}{$\mathrm{LC}_{50}(\mu \mathrm{g} / \mathrm{mL})$} \\
\hline & $24 \mathrm{~h}$ & $48 \mathrm{~h}$ \\
\hline B. myrtifolia Methanol & $4963 \pm 87$ & $5016 \pm 135$ \\
\hline B. myrtifolia Water & $4553 \pm 74$ & $5340 \pm 113$ \\
\hline S. anisatum Methanol & $5576 \pm 121$ & $5708 \pm 147$ \\
\hline S. anisatum Water & $4738 \pm 107$ & $5120 \pm 143$ \\
\hline Potassium dichromate & $88 \pm 5$ & $82 \pm 4$ \\
\hline
\end{tabular}

Results represent the mean \pm SEM of triplicate determinations.

across a range of concentrations in the Artemia nauplii bioassay (Table 3). For comparison, serial dilutions of potassium dichromate were also tested. All B. myrtifolia and S. anisatum extracts were determined to be nontoxic, with $\mathrm{LC}_{50}$ values substantially greater than $1000 \mu \mathrm{g} / \mathrm{mL}$ following $24 \mathrm{~h}$ exposure. Extracts with an $\mathrm{LC}_{50}$ of greater than $1000 \mu \mathrm{g} / \mathrm{mL}$ towards Artemia nauplii have previously been defined as being nontoxic. ${ }^{29}$

\section{DISCUSSION}

Plant derived remedies are becoming increasingly sought after in the treatment of a myriad of diseases and disorders due both to their perception of greater safety than synthetic drugs, and the failure of current drug regimens to effectively treat many diseases. This current study reports on the growth inhibitory properties of B. myrtifolia and S. anisatum leaf extracts against a panel of pathogenic bacteria, and on their toxicity. The gram positive and gram negative bacteria tested in this study demonstrated similar susceptibilities towards the B. myrtifolia and S. anisatum 
extracts, albeit with a slightly higher susceptibility for the gram negative bacteria. Many previous studies with other plant species report a greater susceptibility towards solvent extracts for South American, ${ }^{33}$ African $^{34}$ and Australian plant extracts. ${ }^{35,36}$

Our study examined the ability of B. myrtifolia and S. anisatum extracts to inhibit the growth of a panel of medicinally important bacterial pathogens. The aqueous extracts of both species were identified as being particularly potent inhibitors of $P$. mirabilis. MIC values against the clinical $P$. mirabilis isolate strain of 125 and $105 \mu \mathrm{g} / \mathrm{mL}$ were determined for the aqueous $B$. myrtifolia and $S$. anisatum extracts respectively. As $P$. mirabilis can trigger rheumatoid arthritis in genetically susceptible individuals $^{31,32}$ these extracts have potential for the development of rheumatoid arthritis inhibitory therapies. The methanolic S. anisatum extract also displayed moderate $K$. pneumoniae growth inhibitory properties (MIC values $<5000 \mu \mathrm{g} / \mathrm{mL}$ for both the reference and clinical strains). As K. pneumoniae can trigger ankylosing spondylitis in genetically susceptible individuals $\mathrm{s}^{37,38}$ this extract may also be useful in the prevention of ankylosing spondylitis. Furthermore, the methanolic $S$. anisatum extract was a good inhibitor of $S$. pyogenes growth. $S$. pyogenes may cause a myriad of diseases including streptococcal pharyngitis, impetigo and rheumatic heart disease, depending on which tissue it infects. ${ }^{39,40}$ Thus, the methanolic S. anisatum extract may be useful in the prevention of these diseases.

Aside from inhibition of the bacterial triggers of the autoimmune disease discussed above, the B. myrtifolia and S. anisatum extracts also were moderate to good inhibitors of several other bacterial pathogens. Both the aqueous and methanolic S. anisatum extracts inhibited E. coli growth. However, the methanolic extract displayed the greater efficacy, with MICs of 893 and $1255 \mu \mathrm{g} / \mathrm{mL}$ against the reference and clinical isolate strains respectively. Thus, this extract has potential in the treatment of diarrhoea and dysentery caused by enteric E. coli infections, as well as urinary tract E. coli infections. The aqueous and methanolic B. myrtifolia extracts were also moderate to good inhibitors of $S$. aureus and S. epidermidis growth (MICs $1750-2750 \mu \mathrm{g} / \mathrm{mL}$ ). As both of these bacteria are skin disease pathogens, the B. myrtifolia extracts also may have applications as topical treatments of these diseases.

Whilst an investigation of the phytochemistry of the B. myrtifolia and S. anisatum extracts was beyond the scope of our study, other plants of the family Myrtaceae are well known for their high terpenoid contents. In particular, high monoterpenoid contents have been reported for many Myrtaceae spp. ${ }^{1}$ Monoterpenes have been reported to exert a wide variety of biological effects including antibacterial, antifungal, anti-inflammatory and anti-tumour activities ${ }^{16}$ and therefore may contribute to the bacterial growth inhibitory activity of the B. myrtifolia and S. anisatum extracts reported here. A wide variety of monoterpenoids including camphor, carvone, cineole, borneol, menthone, pinene, terpinene, as well as their derivatives, inhibit the growth of an extensive panel of pathogenic and food spoilage bacteria. ${ }^{41}$ Interestingly, several of these monoterpenoids have also been reported to suppress NF- $\kappa B$ signaling (the major regulator of inflammatory diseases). ${ }^{42-45}$ This may be particularly relevant for the extracts which inhibited $P$. mirabilis (a bacterial trigger of rheumatoid arthritis $)^{31,32}$ and K. pneumoniae (a trigger of ankylosing spondylitis). ${ }^{37,38}$ The terpene components in these extracts may have a pleuripotent mechanism in blocking the autoimmune inflammatory diseases and relieving its symptoms by acting on both the initiator and downstream inflammatory stages of the disease. Further phytochemical evaluation studies and bioactivity driven isolation of active components is required to further evaluate the mechanism(s) of bacterial growth inhibition.

Another commonality between the inhibitory B. myrtifolia and S. anisatum extracts was that all contained moderate levels of tannins. Many studies have reported potent growth inhibitory activities for a number of tannin compounds. Gallotannins have been reported to inhibit the growth of a broad spectrum of bacterial species ${ }^{46}$ through a variety of mechanisms including binding cell surface molecules including lipotoichoic acid and proline-rich cell surface proteins, ${ }^{47,48}$ and by inhibiting glucosyltransferase enzymes. ${ }^{49}$ Elligitannins are also highly potent inhibitors of bacterial growth, with MIC values as low as $62.5 \mu \mathrm{g} / \mathrm{mL}^{46,48}$ Ellagitannins have also been reported to function via several antibiotic mechanisms including interaction with cytoplasmic oxidoreductases and by disrupting bacterial cell walls. ${ }^{46,48}$ Thus, it is likely that multiple compounds within the B. myrtifolia and S. anisatum extracts may contribute to the inhibition of $S$. pyogenes growth.

The findings reported here also demonstrate that all of the B. myrtifolia and S. anisatum extracts were nontoxic towards Artemia franciscana nauplii, with LC $_{50}$ values substantially $>1000 \mu \mathrm{g} / \mathrm{mL}$. Extracts with $\mathrm{LC}_{50}$ values $>1000 \mu \mathrm{g} / \mathrm{mL}$ towards Artemia nauplii are defined as being nontoxic. ${ }^{29}$ Whilst our preliminary toxicity studies indicate that these extracts may be safe for therapeutic use, studies using human cell lines are required to further evaluate the safety of these extracts. Furthermore, whilst these studies have demonstrated the potential of the B. myrtifolia and $S$. anisatum extracts in the development of future antibiotic chemotherapeutics for the prevention and treatment of urinary tract infections, autoimmune diseases (particularly rheumatoid arthritis and ankylosing spondylitis) and some skin diseases, more work is required to isolate the inhibitory components and determine the mechanism of inhibition.

\section{CONCLUSION}

The results of this study demonstrate the potential of the B. myrtifolia and $S$. anisatum extracts as inhibitors of pathogenic bacteria growth. Furthermore, their lack of toxicity indicates than they are safe for internal as well as topical treatment. Further studies aimed at the purification and identification of bioactive components are needed to examine the mechanisms of action of these agents.

\section{ACKNOWLEDGEMENTS}

The authors are grateful to Philip Cameron for providing the B. myrtifolia and S. anisatum leaves used in this study, and to Michelle Mendell and Jane Gifkins for the gift of the clinical isolate bacterial strains. Financial support for this work was provided by the Environmental Futures Research Institute and the School of Natural Sciences, Griffith University, Australia.

\section{CONFLICT OF INTEREST}

The authors report no conflicts of interest.

\section{ABBREVIATIONS}

DMSO: Dimethyl sulfoxide; $\mathbf{L C}_{50}$ : The concentration required to achieve 50\% mortality; MIC: Minimum inhibitory concentration.

\section{REFERENCES}

1. Cock IE. Medicinal and aromatic plants-Australia. In Ethnopharmacology, Encyclopedia of Life Support Systems (EOLSS), 2011. Developed under the auspices of UNESCO. Oxford, UK: EOLSS Publishers; 2011. Available from: http://www. eolss.net. Accessed 1 April 2013.

2. Cock IE. Antibacterial activity of selected Australian plant species. The Internet Journal of Microbiology. 2008;6:2

3. Cock IE. Antibacterial and antifungal activity of Eucalyptus major and Eucalyptus baileyana methanolic extracts. The Internet Journal of Microbiology. 2009. $6: 1$

4. Cock IE. Antimicrobial activity of Callis temon citrinus and Callistemon salignus methanolic extracts. 2012 Pharmacognosy Communications. 2012;2(3):50-7. DOI: $10.5530 /$ pc.2012.3.11

5. Wright MH, Matthews B, Arnold MSJ, et al.The prevention of fish spoilage by high antioxidant Australian culinary plants: Shewanella putrefaciens growth inhibition. 
International Journal of Food Science and Technology 2016; DOI: 10.1111/ ijfs. 13026

6. Sautron C, Cock IE. Antimicrobial activity and toxicity of Syzygium australe and Syzygium leuhmanii fruit extracts. Pharmacognosy Communications. 2014;4(1):53-60. DOI: 10.5530/pc.2014.1.8

7. Chikowe G, Mpala L, Cock IE. Antibacterial activity of selected Australian Syzygium species. Pharmacognosy Communications. 2013;3(4):77-83. DOI: 10.5530/pc.2013.4.11

8. Cock IE. Antimicrobial activity of Syzygium australe and Syzygium leuhmannii methanolic extracts. Pharmacognosy Communications. 2012;2(2):71-7. DOI: 10.5530/pc.2012.2.11

9. Webb MA. Bush Sense. Australian Essential oils and aromatic compounds. Griffin Press, 2000, Adelaide Australia.

10. Cock IE. Antimicrobial activity of Backhousia citriodora (lemon myrtle) methanolic extracts. Pharmacognosy Communications. 2013;3(2):58-63. DOI: 10.5530/ pc.2013.2.12

11. Wilkinson JM, Hipwell M, Ryan T, Cavanagh HMA. Bioactivity of Backhousia citriodora: antibacterial and antifungal activity. Journal of Agriculture and Food Chemistry. 2003;51(1):76-81.

12. Ryan T, Cavanagh HMA, Wilkinson JM. Antimicrobial activity of Backhousia citriodora oil. Simply Essential 2000; 38: 6-8.

13. Opdyke DLJ. Citral. Monographs on fragrance raw materials. Food and Cosmetics Technology. 1976;14:615.

14. Inouye S, Takizawa T, Yamaguchi H. Antimicrobial activity of essential oils and their major constituents against respiratory tract pathogens by gaseous contact. Journal of Antimicrobial Chemotherapy. 2001;47(5):565-73

15. Kim JM, Marshall MR, Cornell JA, Preston JF, Wei Cl. Antibacterial activity of carvacrol, citral and geraniol against Salmonella typhimurium in culture media and in fish cubes. Journal of Food Science. 1995;60(6):1364-8.

16. Cock IE. The phytochemistry and chemotherapeutic potential of Tasmannia lanceolata (Tasmanian pepper): A review. Pharmacognosy Communications. 2013;3(4):1-13. DOI: 10.5530/pc.2013.4.3

17. Kubo I, Fujita K. Naturally occurring anti-Salmonella agents. Journal of Agriculture and Food Chemistry. 2001;49(12):5750-4.

18. Griffin SG, Markham JL, Leach DN. An agar dilution method for the determination of the minimum inhibitory concentration of essential oils. Journal of Essential Oil Research. 2000;12(2):249-55

19. Hammer KA, Carson CF, Riley TV. Antimicrobial activity of essential oils and other plant extracts. Journal of Applied Microbiology. 1999;86(6):985-90.

20. Kalt FR, Cock IE. Gas chromatography-mass spectroscopy analysis of bioactive Petalostigma extracts: Toxicity, antibacterial and antiviral activities. Pharmacognosy Magazine. 2014;10(37 Supp):S37-S49. DOI: 10.4103/0973-1296.127338

21. Vesoul J, Cock IE. The potential of Bunya nut extracts as antibacterial functional foods. Pharmacognosy Communications. 2012;2(1):72-9. DOI: 10.5530/ pc.2012.1.3

22. Hart C, Ilanko P, Sirdaarta J, et al. Tasmannia stipitata as a functional food/natural preservative: Antimicrobial activity and toxicity. Pharmacognosy Communications. 2014;4(4):33-47. DOI: 10.5530/pc.2014.4.4

23. Winnett $\mathrm{V}$, Boyer $\mathrm{H}$, Sirdaarta $\mathrm{J}$, et al. The potential of Tasmannia lanceolata as a natural preservative and medicinal agent: Antimicrobial activity and toxicity. Pharmacognosy Communications. 2014:4(1):42-52. DOI: 10.5530/pc.2014.1.7

24. Arkhipov A, Sirdaarta J, Rayan P, et al. An examination of the antibacterial, antifungal, anti-Giardial and anticancer properties of Kigelia africana fruit extracts. Pharmacognosy Communications. 2014:4(3):62-76. DOI: 10.5530/pc.2014.3.7

25. Courtney R, Sirdaarta J, Matthews B, etal. Tannin components and inhibitory activity of Kakadu plum leaf extracts against microbial triggers of autoimmune inflammatory diseases. Pharmacognosy Journal. 2015;7(1):18-31. DOI: 10.5530/ pj.2015.7.2

26. Sirdaarta J, Matthews B, Cock IE. Kakadu plum fruit extracts inhibit growth of the bacterial triggers of rheumatoid arthritis: Identification of stilbene and tannin components. Journal of Functional Foods. 2015;17:610-20. DOI: 10.1016/j.ff.2015.06.019

27. Cock IE. Antimicrobial activity of Acacia aulacocarpa and Acacia complanta methanolic extracts. Pharmacognosy Communications. 2012;2(1):66-71. DOI: 10.5530/pc.2012.1.12

28. Ruebhart DR, Wikramasinghe WA, Cock IE. Protective efficacy of the antioxidants vitamin E and Trolox against Microcystis aeruginosa and microcystin-LR in Artemia franciscana nauplii. Journal of Toxicology and Environmental Health Part A. 2009;72(24):1567-75.

29. Cock IE, Ruebhart DR. Comparison of the brine shrimp nauplii bioassay and the ToxScreen-II test for the detection of toxicity associated with Aloe vera (Aloe barbadensis Miller) leaf extract. Pharmacognosy Research. 2009;1(2):98-101.

30. Cock IE. Assessment of the toxicity of selected Australian native plant extracts using the Artemia franciscana nauplii bioassay. The Internet Journal of Toxicology. 2008;5:2.

31. Cock IE, van Vuuren SF. Anti-Proteus activity of some South African plants: Their potential for the prevention of rheumatoid arthritis. Inflammopharmacology. 2014;22(1):23-36. DOI: 10.1007/s10787-013-0179-3

32. Ebringer A, Rashid T. Rheumatoid arthritis is an autoimmune disease triggered by Proteus urinary tract infection. Clinical and Developmental Immunology. 2006;13(1):41-8.

33. Mohanty S, Cock IE. Evaluation of the antibacterial activity of Mycaria caulifloria methanolic leaf and fruit extracts. The Internet Journal of Microbiology 2009; $7(2)$

34. Cock IE, van Vuuren SF. South African food and medicinal plant extracts as potential antimicrobial food agents. Journal of Food Science and Technology. 2015;52(11):6879-99. DOI: 10.1007/s13197-015-1806-3

35. Kukkonen L, Cock IE. An examination of the medicinal potential of Scaevola spinescens: Toxicity, antibacterial, and antiviral activities. Pharmacognosy Research. 2011;3(2):85-94. DOI: 10.4103/0974-8490.81955

36. Vesoul J, Cock IE. An examination of the medicinal potential of Pittosporum phylliraeoides: Toxicity, antibacterial, and antifungal activities. Pharmacognosy Communications. 2011;1(2):8-17. DOI: 10.5530/pc.2011.2.3

37. Cock IE, van Vuuren SF. The potential of selected South African plants with antiKlebsiella activity for the treatment and prevention of ankylosing spondylitis. Inflammopharmacology. 2015;23(1):21-35. DOI: 10.1007/s10787-014-0222-z

38. Ebringer A, Rashid T, Wilson C. Ankylosing spondylitis as an auto-immune disease linked to intestinal Klebsiellaq infection: prospects for a new therapeutic approach. Current Rheumatology Reviews. 2006;2(1):55-68.

39. Gerber MA, Baltimore RS, Eaton CB. Prevention of rheumatic fever and diagnosis and treatment of acute Streptococcal pharyngitis. A scientific statement from the American Heart Association Rheumatic Fever, Endocarditis, and Kawasaki Disease Committee of the Council on Cardiovascular Disease in the Young, the Interdisciplinary Council on Functional Genomics and Translational Biology, and the Interdisciplinary Council on Quality of Care and Outcomes Research: Endorsed by the American Academy of Pediatrics. Circulation. 2009;119(11):1541-51.

40. Wright $\mathrm{MH}$, Arnold MSJ, Lee CJ, et al. Qualitative phytochemical analysis and antibacterial activity evaluation of Indian Terminalia spp. against the pharyngitis causing pathogen Streptococcus pyogenes. Pharmacognosy Communications. 2016;6(2):85-92. DOI: 10.5530/pc.2016.2.6

41. Bakkali F, Averbeck $S$, Averbeck D. Biological effects of essential oils - A review. Food and Chemical Toxicology. 2008:46(2):446-75.

42. Salminen A, Lehtonen M, Suuronen T. Terpenoids: Natural inhibitors of NF- $\mathrm{KB}$ signalling with anti-inflammatory and anticancer potential. Cell and Molecular Life Sciences. 2008;65(19):2979-99

43. Lu XG, Zhan LB, Feng BA. Inhibition of growth and metastasis of human gastric cancer implanted in nude mice by d-limonene. World Journal of Gastroenterology. 2004;10(14):2140-4

44. Crowell PL. Prevention and therapy of cancer by dietary monoterpenes. Journal of Nutrition. 1999;129(3):775S-8S

45. Zhou JY, Tang FD, Mao GG. Effect of a-pinene on nuclear translocation of NF-אB in THP-1 cells. Acta Pharmacologica Sinica. 2004;25(4):480-4.

46. Buzzini P, Arapitsas P, Goretti M. Antimicrobial activity of hydrolysable tannins. Mini-Reviews in Medicinal Chemistry. 2008;8:1179-87.

47. Wolinsky LE, Sote EO. Isolation of natural plaque-inhibiting substances from 'Nigerian chewing sticks'. Caries Research. 1984;18(3):216-25

48. Hogg SD, Embery G. Blood-group-reactive glycoprotein from human saliva interacts with lipoteichoic acid on the surface of Streptococcus sanguis cells. Archives in Oral Biology. 1982;27(3):261-8.

49. Wu-Yuan CD, Chen CY, Wu RT. Gallotannins inhibit growth, water-soluble glucan synthesis, and aggregation of Streptococci mutans. Journal of Dental Research. $1988 ; 67(1): 51-5$ 
PICTORIAL ABSTRACT

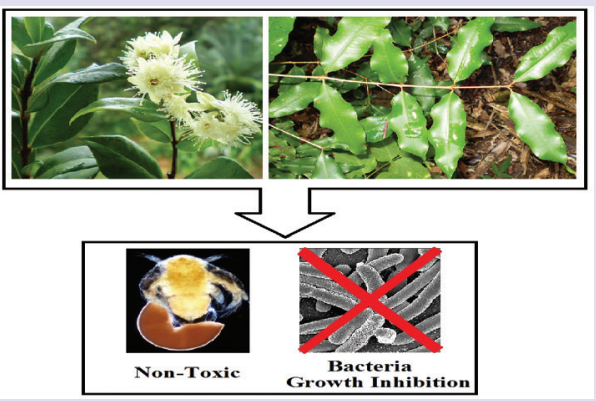

\section{SUMMARY}

- B. myrtifolia and S. anisatum leaf extracts inhibited the growth of a wide range of bacterial species.

- Growth of both gram positive and gram negative bacteria was inhibited to approximately the same extent.

- B. myrtifolia and S. anisatum extracts were particularly potent inhibitors of $P$. mirabilis growth.

- All extracts were nontoxic in the Artemia franciscana nauplii bioassay.

\section{ABOUT AUTHORS}

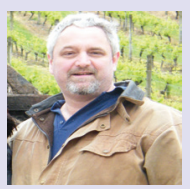

Dr lan Cock leads a research team in the Environmental Futures Research Institute and the School of Natural Sciences at Griffith University, Australia. His research involves bioactivity and phytochemical studies into a variety of plant species of both Australian and international origin, including Aloe vera, South Asian and South American tropical fruits, as well as Australia plants including Scaevola spinescens, Pittosporum phylliraeoides, Terminalia ferdinandiana (Kakadu plum), Australian Acacias, Syzygiums, Petalostigmas and Xanthorrhoea johnsonii (grass trees). This range of projects has resulted in nearly 200 publications in a variety of peer reviewed journals. 